\title{
Elementos-traço em águas superficiais e tecnossolos como geoindicadores de mudanças ambientais antropogênicas em sistema fluvial da Baixada Fluminense
}

\section{Trace elements in surface water and technosols as geoindicators of anthropogenic environmental changes in a river system of the Baixada Fluminense}

\author{
Niriele Bruno Rodrigues ${ }^{* 1} \bowtie\left(D\right.$, Flávia de Almeida Vieira ${ }^{\circledR} \bowtie(\mathbb{D}$, \\ Laura Delgado Mendes $1 \square$ (ID \\ ${ }^{1}$ Instituto Multidisciplinar, Universidade Federal Rural do Rio de Janeiro, Nova Iguaçu, \\ Rio de Janeiro, Brasil \\ 2Instituto Federal de Educação, Ciência e Tecnologia do Rio de Janeiro, Cidade do Rio de \\ Janeiro, Rio de Janeiro, Brasil \\ E-mail: flavia.vieira@ifrj.edu.br (FAV); lauradmendes@gmail.com (LDM) \\ *E-mail para correspondência: nirielebr@yahoo.com.br
}

Recebido (Received): 16/06/2020 Aceito (Accepted): 06/02/2021

\begin{abstract}
Resumo: Nas últimas décadas, as intervenções antrópicas têm alterado o ciclo dos processos naturais que ocorrem na superfície terrestre, com impactos que configuram o meio físico. O objetivo da pesquisa foi identificar e analisar geoindicadores (geoquímicos) de mudanças ambientais antropogênicas nos compartimentos ambientais (água e sedimentos) na bacia hidrográfica do rio Botas. A metodologia foi baseada na seleção de cinco pontos no perfil longitudinal do rio e análises laboratoriais (sedimento de leito e planície e água) para determinação dos elementos-traço: $\mathrm{Cr}, \mathrm{Cu}, \mathrm{Ni}, \mathrm{Cd}, \mathrm{Pb}$ e $\mathrm{Zn}$. Os resultados indicaram a poluição da água e sedimentos pelos elementos $\mathrm{Cr}, \mathrm{Cu}, \mathrm{Pb}$ e $\mathrm{Zn}$, com base nos valores de referência da National Oceanic and Atmospheric Administration (NOAA) (BUCHMAN, 2008) e CONAMA (2005). Observou-se uma variabilidade de 0,1 a $1,5(\mathrm{Cr}), 0$ a $0,2(\mathrm{~Pb})$ e 0 a 0,2 ( $\mathrm{Zn})$ para água $(\mathrm{mg} / \mathrm{l})$; em sedimentos de leito $(\mathrm{mg} / \mathrm{kg})$ de 5,8 a 42,2 $(\mathrm{Cr}), 2,7$ a 12,4 $(\mathrm{Pb}), 1,3$ a $15(\mathrm{Cu})$ e 22,9 a $69(\mathrm{Zn})$; e, para sedimentos de planície $(\mathrm{mg} / \mathrm{kg})$ obteve-se a variação de 5,2 a 24,6 (Cr), 2 a 36,5 $(\mathrm{Pb}), 5,7$ a 17,3 $(\mathrm{Cu})$ e 20 a 242,2 (Zn), com indicação de aumento gradativo em direção à jusante do rio. Considera-se que os pontos poluídos têm interferência de esgoto industrial e doméstico in natura, associados aos diversos usos e cobertura da terra, que corroboram com o aumento de elementos-traço. Tais resultados indicam a degradação antropogênica em sistema fluvial associado ao longo histórico de degradação ambiental.
\end{abstract}

Palavras-chave: Geociências; Antropoceno; Geoquímica; Ambiente urbano.

Abstract: In recent decades, anthropic interventions have altered the cycle of natural processes that occur on the Earth's surface, with impacts that configure the physical environment. The objective of the research was to identify and analyze geoindicators (geochemical) of anthropogenic environmental changes in the environmental compartments (water and sediments) of the Botas River basin. The methodology was based on the selection of five points in the longitudinal profile of the river and laboratory analysis (bed sediment, plain and water) to determine the trace elements: $\mathrm{Cr}, \mathrm{Cu}, \mathrm{Ni}, \mathrm{Cd}, \mathrm{Pb}$ and $\mathrm{Zn}$. The results indicated water and sediment pollution by $\mathrm{Cr}, \mathrm{Cu}, \mathrm{Pb}$ and $\mathrm{Zn}$ elements, based on National Oceanic and Atmospheric Administration (NOAA) reference values (BUCHMAN, 2008) and CONAMA (2005). A variability of 0.1 to $1.5(\mathrm{Cr}), 0$ to $0.2(\mathrm{~Pb})$ and 0 to $0.2(\mathrm{Zn})$ was observed for water $(\mathrm{mg} / \mathrm{l})$; in bed sediments $(\mathrm{mg} / \mathrm{kg})$ from 5.8 to $42.2(\mathrm{Cr}), 2.7$ to $12.4(\mathrm{~Pb}), 1.3$ to $15(\mathrm{Cu})$ and 22.9 to $69(\mathrm{Zn})$; and, for plain sediments $(\mathrm{mg} / \mathrm{kg})$ a variation of 5.2 to $24.6(\mathrm{Cr}), 2$ to $36.5(\mathrm{~Pb}), 5.7$ to $17.3(\mathrm{Cu})$ and 20 to $242.2(\mathrm{Zn})$ was obtained, with indication of gradual increase towards the downstream of the river. It is considered that the polluted points have been affected by industrial and domestic sewage in natura, associated with different types of land use and land 
cover, which corroborate with the increase of trace elements. Such results indicate anthropogenic degradation in river systems associated with a long history of environmental degradation.

Keywords: Geosciences; Anthropocene; Geochemistry; Urban environment.

\section{Introdução}

A degradação de solos e de águas superficiais em sistemas fluviais de áreas urbanizadas é uma problemática importante e preocupante na atualidade. Nelas, os fatores de contaminação, como o despejo de efluentes domésticos e industriais in natura nos corpos hídricos, podem também estar atrelados aos condicionantes fisiográficos, especialmente quando afetadas por eventos de enchentes, inundações e alagamentos (AMARAL; GUTJAHR, 2011), o que compromete ainda mais a saúde ambiental do sistema e da população que habita essas planícies tecnogênicas.

As atividades antrópicas têm interferido nos processos naturais que ocorrem na superfície terrestre criando novas camadas pedológicas com comportamento distinto do que ocorre em solos com uma gênese natural. A espécie humana tem perturbado os processos pedogeomorfológicos (desenvolvimento solo, dinâmica da água e processos erosivos) através da ação direta e indireta sobre o mesmo, com processos novos que não existiriam sem a interferência humana. Ocorre uma maior pressão sobre esse recurso natural, o "solo" (receptor de resíduos, base para ocupação e uso agrícola). Portanto, modificações tecnogênicas por ações antrópicas que afetam o equilíbrio ambiental dessas coberturas superficiais terrestres são tão possíveis quanto importantes serem analisadas em ambiente urbano/industrial.

Os tecnossolos ou solos urbanos possuem propriedades e pedogênese de origem técnica, contendo em sua estrutura materiais manufaturados (algo no solo reconhecidamente feito ou fortemente alterado por seres humanos ou extraído de maiores profundidades), ou são vedadas por material duro técnica (material duro criado por seres humanos, que têm propriedades ao contrário de rocha natural) (CRAUL, 1985; IUSS Working Group, 2014).

O processo de urbanização tem atuado na gênese desses solos, que apresentam distúrbios na morfologia estrutural (variabilidade de materiais manufaturados, metais pesados, decapitações de horizontes) (CRAUL, 1985). Sendo assim, representam o conjunto de corpos localizados em áreas urbanizadas ou industriais e influenciadas, suscetíveis às interferências de todo tipo de materiais antrópicos ou que já tiveram em algum momento de sua história ambiental o ser humano como agente modificador de suas características morfológicas naturais, criando-se, portanto, uma nova camada com estruturação pedológica diferenciada nos aspectos morfológicos, biológico e físico-químico, tornando-os, em muitos casos, um vetor de doenças para a sociedade (IUSS Working Group, 2014).

Nas últimas décadas, com o desenvolvimento tecnológico e industrial, aumento do crescimento demográfico e, por conseguinte, da demanda por recursos naturais pela sociedade, as mudanças ambientais se agravaram, ocasionando diversas alterações de segunda natureza no meio ambiente. Nesse contexto, com o intuito de averiguar os processos de mudanças ambientais que se desenvolviam em curto período, em conjunto com as características geomorfológicas e geológicas, foi proposto o conceito de geoindicadores que, conforme Coltrinari e McHall (1995), são marcadores ambientais que possuem a função de obter informações relacionadas às condições dos sistemas ambientais e os intervalos das mudanças naturais e as antropogênicas em diferentes escalas.

Diante disso, o objetivo do presente artigo é identificar e analisar geoindicadores (geoquímicos) de mudanças ambientais antropogênicas nos compartimentos ambientais (água e sedimentos) ao longo do rio Botas, em uma sub-bacia do rio Iguaçu, na Região Hidrográfica da Guanabara - RH-V (INEA/CERHI, 2013), Baixada Fluminense. A partir da análise de concentrações pseudo-totais de elementos-traço $(\mathrm{Cr}, \mathrm{Cu}$, $\mathrm{Cd}, \mathrm{Ni}, \mathrm{Pb}$ e $\mathrm{Zn}$ ) buscou-se avaliar os efeitos adversos desses elementos nas coberturas superficiais e no sistema fluvial e, por conseguinte, na saúde ambiental do geossistema.

Estão parcialmente integrados na área de estudo os municípios de Nova Iguaçu e Belford Roxo (Figura 1), situados na denominada Baixada Fluminense, na Região Metropolitana do Estado do Rio de Janeiro (RMRJ) (RIO DE JANEIRO, 2013; FNEM, 2018), entre as coordenadas $22^{\circ} 45^{\prime} 33^{\prime \prime}$, de latitude sul, e $43^{\circ} 27^{\prime}$ 04", de longitude oeste. Inserida num contexto de densa urbanização, possui um histórico de antropização especialmente nas planícies fluviais, em especial nas Áreas de Preservação Permanente (APPs) de rios, que são áreas de especial atenção reconhecidas pelo Código Florestal Brasileiro (BRASIL, 2012). 
Os referidos compartimentos ambientais de águas superficiais e solos têm sofrido diversas interferências antrópicas devido à complexidade de atividades exercidas no meio urbano e que têm alterado as suas características (físicas, químicas e biológicas), comprometendo funcionalidades e a capacidade de resiliência do sistema ambiental (PEDRON et al. 2004, LADEIRA, 2012).

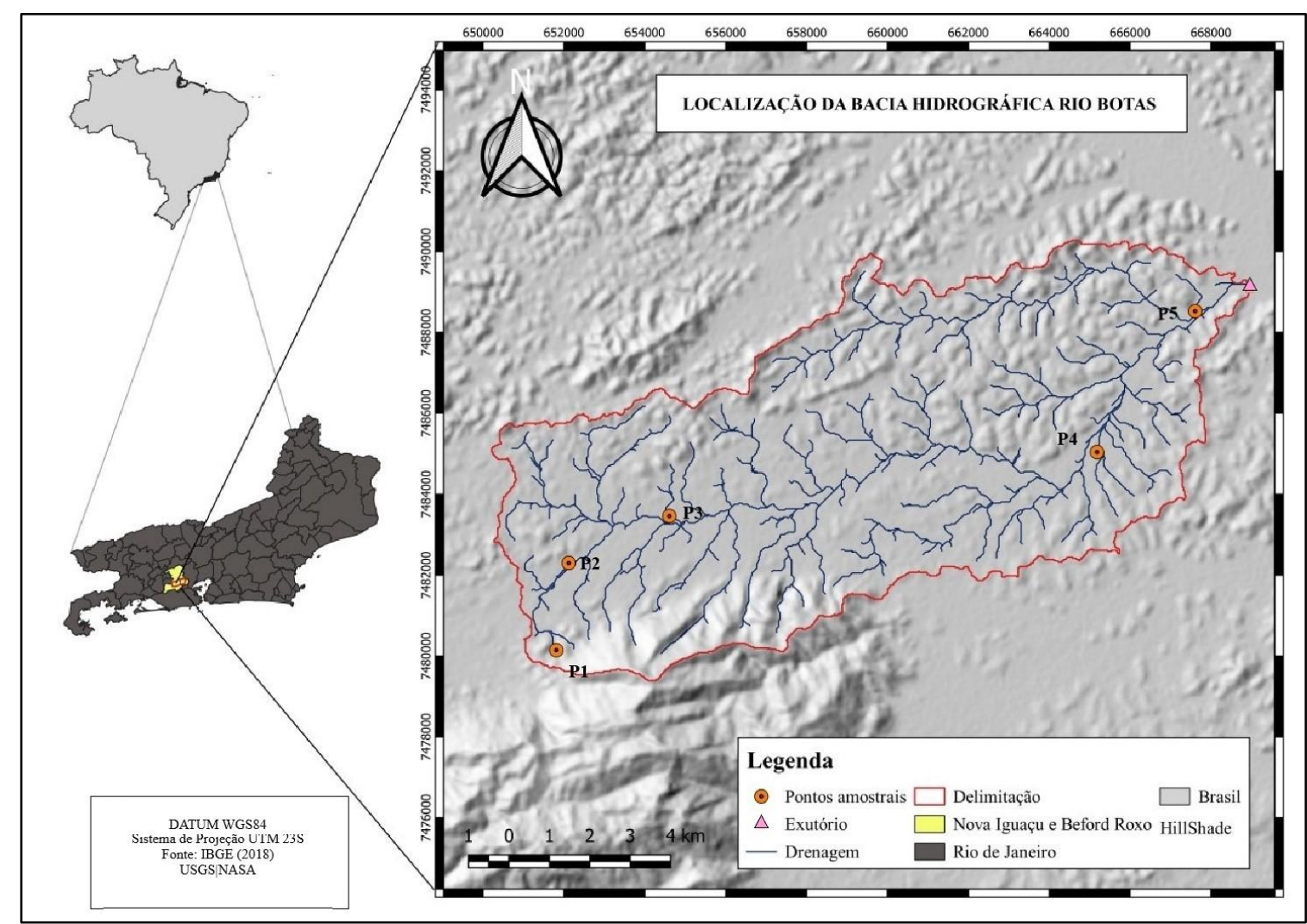

Figura 1: Localização dos pontos de amostragem na bacia hidrográfica do rio Botas, com fins de coleta de material para as análises laboratoriais.

No que tange à dinâmica de transporte e deposição dos sedimentos e dos poluentes, os metais-traço, quando disponibilizados em altas concentrações no meio ambiente, acarretam diversos efeitos de baixa-alta frequência na saúde ambiental da bacia hidrográfica, e são transportados e depositados por meio da calha fluvial. Uma vez na calha fluvial, os poluentes adsorvidos aos sedimentos poderão ser transportados por longas distâncias e, quando presentes em altas concentrações, poderão provocar graves problemas ambientais (POLETO; CASTILHOS, 2008). Portanto, ocorre a problemática de ordem física (assoreamento, inundações urbanas) e também química (transporte de poluentes) nos corpos hídricos urbanos (POLETO, 2004), em especial no contexto da bacia hidrográfica do rio Botas, que sofreu intensas modificações agravadas pela ausência do saneamento básico, o que faz com que os rios sejam vetores de doenças de veiculação hídrica (BRASIL, 2010; FIOCRUZ, 2010; TRATA BRASIL, 2018; 2019a), principalmente nos eventos de inundação que podem afetar grande área da bacia de drenagem. Destaca-se que as duas cidades dessa bacia de drenagem estão entre as 20 piores em saneamento básico entre as 100 maiores cidades do país (TRATA BRASIL, 2019b). Na avaliação mais recente, Belford Roxo se manteve entre as 10 piores e apenas Nova Iguaçu obteve uma pequena melhora ao se posicionar entre as últimas 30 e não mais entre as 20 cidades com os piores indicadores, como pode ser observado em TRATA BRASIL (2020).

Nesse sentido, estudos como os de Cesar et al. (2012), Da Silva et al. (2017), Nascimento et al. (2018) e Dos Reis et al. (2020), sob o viés de análise de indicadores geoquímicos, oferecem importantes contribuições para a identificação e rastreamento de fontes de contaminação antropogênicas e determinação de concentrações de elementos-traço. Assim, mostra-se necessário o conhecimento de técnicas acerca de identificação de teores de elementos-traço para estudos ambientais em sistemas fluviais, via rastreamento de fontes de origem geogênica e/ou antropogênica para avaliação da dinâmica de poluição e destinação de uso da terra em áreas urbanas. 
Nesse contexto, o presente estudo se faz necessário visto que as intervenções na bacia hidrográfica trazem consigo problemas não só de ordem hidrogeomorfológica, mas também desequilíbrios ambientais que impactam a saúde pública, demandando, assim, medidas urgentes de ordenamento territorial e ambiental.

\section{Materiais e métodos}

O desenvolvimento do trabalho foi dividido em quatro etapas que consistiram em: 1) Levantamento bibliográfico; 2) Processamento digital de imagens e documentos cartográficos, executada através do programa QGIS; 3) Trabalho de campo, para o diagnóstico, definição dos cinco (05) pontos amostrais e coleta de material (maio e junho de 2016); e 4) Análises laboratoriais.

A avaliação apresentada sobre os elementos-traço como geoindicadores teve como critério e marcador ambiental do Tecnógeno (PELOGGIA, 2003), o uso e cobertura da terra nos cinco pontos amostrais, utilizando os seguintes compartimentos ambientais: (1) águas superficiais, (2) sedimento de planície de inundação e (3) sedimento de leito.

\subsection{Seleção dos pontos para amostragem}

Os trabalhos de campo tiveram como finalidade a realização de um diagnóstico da área de estudo, assim como registros fotográficos, com o intuito de identificar geoindicadores ambientais que pudessem sinalizar condições de degradação dos solos, além da definição de pontos principais para as amostragens. $\mathrm{O}$ delineamento da malha amostral ao longo do perfil longitudinal do rio Botas foi definido com base no parâmetro de indicação de degradação de uso e cobertura da terra na área amostrada e do contexto da área de contribuição de rios afluentes e impacto antropogênico para aquele ponto. Nessa etapa foram estabelecidos 5 pontos amostrais (Figura 9) e coletadas as amostras de solos morfologicamente alterados na camada de 0-15 $\mathrm{cm}$, sedimentos de planície e leito e água superficial, para a execução da etapa seguinte da pesquisa, visto que, de acordo com Tucci $(2005 ; 2008)$, o desenvolvimento urbano tem originado um ciclo de contaminação procedente de efluentes da população urbana (esgoto doméstico/industrial e o esgoto pluvial). Diante disso, os poluentes que ocorrem em áreas urbanas variam muito, desde compostos orgânicos a metais altamente tóxicos.

\subsection{Coleta e preparo de solos e águas}

As amostragens nos compartimentos ambientais (Figura 2) foram realizadas com os seguintes materiais para prospecção: caixa térmica, draga Van Veen, coletor d'água, frasco âmbar, entre outros materiais necessários. Após a coleta, o material foi armazenado em sacos plástico e frascos, e acondicionado em caixa térmica. Em cada um dos 5 pontos foram coletadas 3 amostras, tendo o total de 15 amostras.

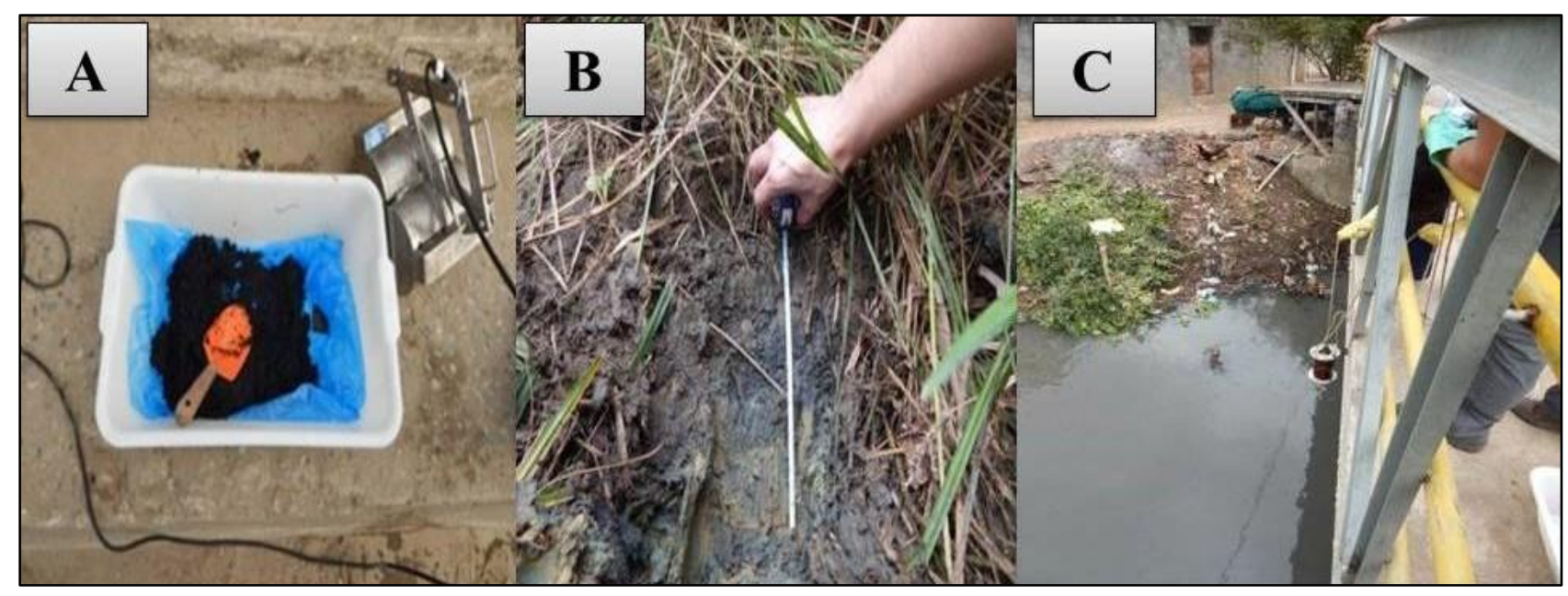

Figura 2: Procedimentos de coleta de amostras de sedimento de leito (A), sedimento de planície (B) e água (C).

Na Figura 2, em A apresenta-se a draga Van Veen, utilizada para coleta de sedimento de leito, manuseada na calha fluvial. Em $\mathbf{B}$ foi utilizado enxada para limpar o terreno e para a extração do solo de 
planície com medida de até 0-15 cm, e por fim em $\mathbf{C}$ foi utilizado o coletor de água com frasco âmbar, para a coleta de água.

\subsection{Análises laboratoriais}

As análises laboratoriais das amostras de sedimento de leito, planície e água visaram averiguar geoindicadores químicos de mudanças ambientais antropogênicas e, por conseguinte, o tratamento de dados obtidos. As análises geoquímicas buscaram identificar condições relacionadas à contaminação pelos seguintes elementos: $\mathrm{Cd}, \mathrm{Cu}, \mathrm{Pb}, \mathrm{Zn}, \mathrm{Cr}$ e $\mathrm{Ni}$ na fração pseudo-total. Os procedimentos laboratoriais de preparo das amostras estão apresentados na Figura 3. Essa etapa da pesquisa foi realizada no Laboratório de Meio Ambiente do Instituto Federal de Educação, Ciência e Tecnologia do Rio de Janeiro (IFRJ) e no Laboratório Química e Poluição de Solo do Departamento de Solos da Universidade Federal Rural do Rio de Janeiro (UFRRJ). As atividades de gabinete, como mapeamentos e integração e análise dos resultados foram realizadas no Laboratório de Geociências e Estudos Ambientais do Instituto Multidisciplinar da UFRRJ.

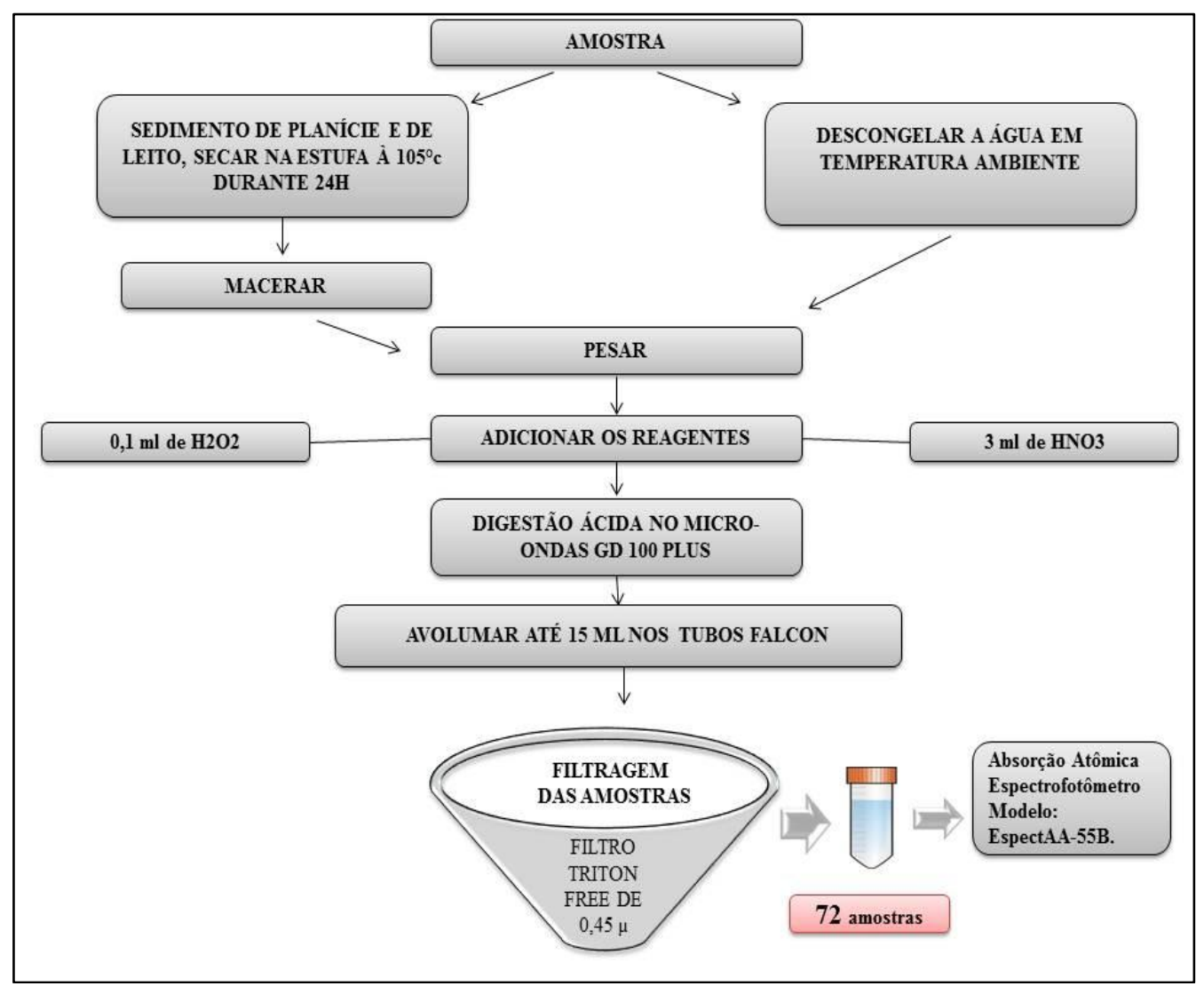

Figura 3: Apresentação esquemática da sequência de procedimentos laboratoriais para digestão ácida.

\subsection{Análise estatística e valores de referência}

Os dados da fração pseudo-total foram tratados por meio de análise estatística, com auxílio do software Microsoft Excel, a fim de determinar os valores médios, concentração final, desvio padrão e limite de detecção. Para validação da metodologia utilizou-se nas análises instrumentais a determinação de limite de detecção (LD) de cada compartimento ambiental analisado. Especificamente no compartimento "água", as concentrações nas amostras de água têm valores inferiores a valores máximos da resolução 357/2005 do Conama (CONAMA, 2005) e, portanto, não apresentam confiança analítica. Nesse caso, serão reportadas como concentração menor do que o limite de detecção "([analito] $<$ LD)".

$\mathrm{O}$ indicador antropogênico no ambiente foi identificado quando os valores de referência foram superiores ao limite permitido. Na análise de impacto ambiental de elementos-traço nos compartimentos ambientais de sedimento de leito e planície foram utilizados como parâmetros os valores orientados da Tabela de Diretriz de Qualidade de Sedimento (DQS), da National Oceanic and Atmospheric Administration (NOAA) (BUCHMAN, 2008), a partir dos critérios de TEL (Thresol effect level) e PEL (Probable effect level). Esses 
dois níveis determinam intervalos de probabilidade de ocorrência de efeitos biológicos adversos no ambiente, determinando o intervalo de ocorrência como, no nível menor TEL considerado de baixa frequência, esperase uma probabilidade quase nula de efeito adverso, já no PEL considerado um nível maior têm se a ocorrência de algum efeito adverso com uma maior frequência. E, para as amostras de água, foram utilizados os parâmetros da Resolução do CONAMA 357/2005 (CONAMA, 2005) que estabelece, de acordo com a classificação dos corpos hídricos, diretrizes para o lançamento de efluentes, estando o rio Botas enquadrado na classe 2 .

\section{Resultados e discussão}

Os valores detectados dos níveis de concentração de Cromo (Cr) nos compartimentos ambientais analisados podem ser observados na Figura 4. Conforme os dados de concentrações totais, observou-se a ocorrência maior de Cr, acima do valor orientador da Tabela de Diretriz de Qualidade de Sedimento (DSQ) (BUCHMAN, 2008), no sedimento de leito do ponto 5, no qual se obteve $42,2 \mathrm{mg} / \mathrm{kg}$, ultrapassando o valor do TEL. Nesse contexto, Silva e Pedrozo (2001, p.40) destacam que "parte do cromo completa o ciclo pela deposição na terra, mas uma significativa quantidade irá depositar-se no oceano, fixando-se no sedimento de seu leito", o que pode indicar a tendência à sua deposição no leito do rio, como observado.

Os demais pontos $(1,2,3$ e 4$)$ apresentaram concentrações abaixo do limite do TEL, assim como todos os pontos amostrais no sedimento de planície, evidenciando uma baixa frequência de efeitos adversos biológicos no meio. Isso pode ocorrer em função da mobilidade do cromo no sedimento de planície ser baixa, devido à pouca formação de complexos insolúveis, conforme afirmam Silva e Pedrozo (2001).

Os pontos que apresentaram violação dos limites estabelecidos evidenciam a interferência antropogênica dos diferentes usos do solo na área de localização como, por exemplo, o ponto 5, que recebe a descarga de efluentes de fontes doméstica e industrial e de todos os afluentes da bacia de drenagem e que contribuem para o enriquecimento do elemento na área.

No ponto 1 a concentração é de $0,8 \mathrm{mg} / \mathrm{l}$ na água, possivelmente devido à proximidade com uma área de extração mineral (pedreira) e/ou material de colúvio da área de coleta, visto que partículas com diâmetro médio de, aproximadamente, $1 \mathrm{~mm}$ e a velocidade de deposição de $0,5 \mathrm{~cm} / \mathrm{segundo}$, são depositadas na terra e na água por sedimentação ou através das chuvas, sendo o cromo liberado no ambiente pelas seguintes fontes: fundições, emissões decorrentes da fabricação e cimento, construção civil, devido aos resíduos provenientes do cimento, cinzas de carvão, fertilizantes entre outros (SILVA e PEDROZO, 2001). Já os pontos 4 e 5, provavelmente sofreram influência dos despejos industriais e domésticos, visto que conforme dados do ranking do saneamento básico de 2015 do Instituto Trata Brasil (2016), o município de Nova Iguaçu estava na $92^{a}$ posição e atualmente está na $72^{\text {a }}$ (TRATA BRASIL, 2020), o que ainda demonstra os graves problemas na gestão de saneamento na bacia hidrográfica.

a)

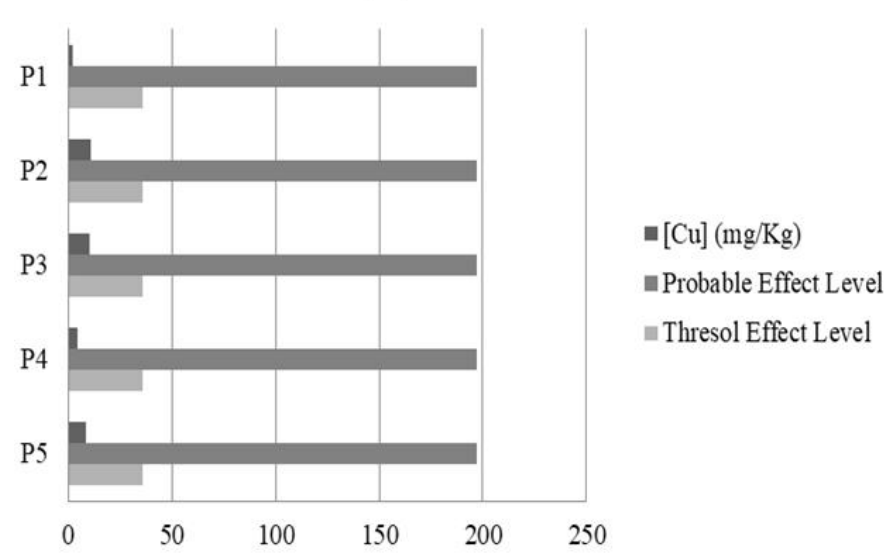


b)

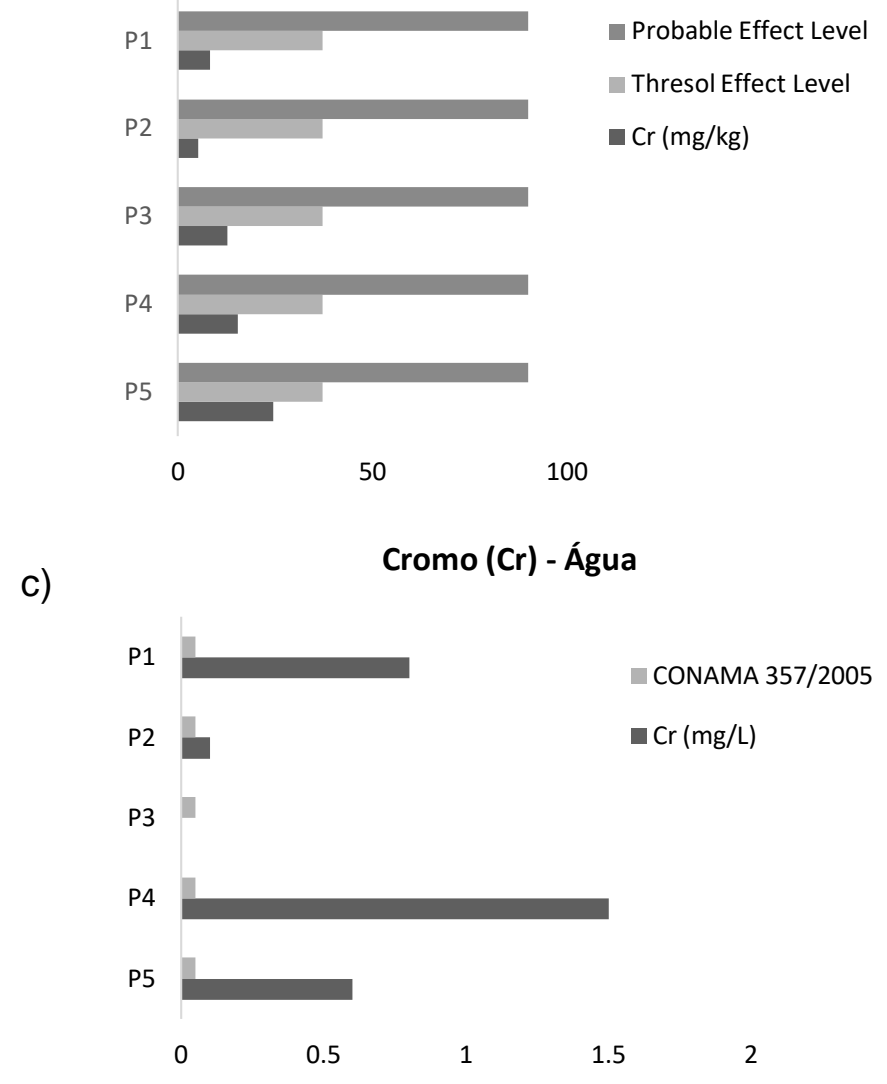

Figura 4: Resultados analíticos do Cromo (Cr), Sedimento de leito (A), Sedimento de planície (B), e Água superficial (C) e comparação com parâmetros de referência de PEL e TEL (BUCHMAN, 2008) e CONAMA (2005).

O cobre é considerado um metal de toxicidade baixa-alta, de acordo com Poleto e Castilhos (2008), sendo proveniente de indústrias de cerâmica, tintas anti-crustantes e micronutrientes. Portanto, o escoamento superficial urbano se torna uma significativa fonte de cobre para o sistema fluvial.

Nenhum dos pontos de sedimentos de leito violou a Diretriz de Qualidade e Sedimento (DSQ) (NOOA) (BUCHMAN, 2008) (Figura 4A), apresentando, portanto, valores abaixo do limite do TEL, ou seja, um nível baixo de frequência de ocorrência de efeitos no meio. Isso parece estar associado ao seu comportamento junto à matéria orgânica, atrelado a hidrodinâmica já que, como visto por Rebello et al. (1988), o cobre tem afinidade com matéria orgânica, devido aos rios e canais transportarem ligantes orgânicos, de processos fotossintéticos, que se encontram sob formas estáveis contendo altos teores de cobre.

No compartimento de sedimento de planície obteve-se concentração elevada de cobre nos pontos 3 e 5 (Figura 5B), devido à contribuição das fontes de resíduos sólidos e lodo de esgoto doméstico presentes na cronodeposição do material das camadas superficiais do sedimento de planície na área de coleta. Para Silva e Pedrozo (2001, p.43), "a maior parte do cobre depositado no solo oriundo da atmosfera, de sua aplicação agrícola, da disposição de resíduos sólidos e de lodo de esgoto está fortemente adsorvida aos primeiros centímetros do solo". 
a)

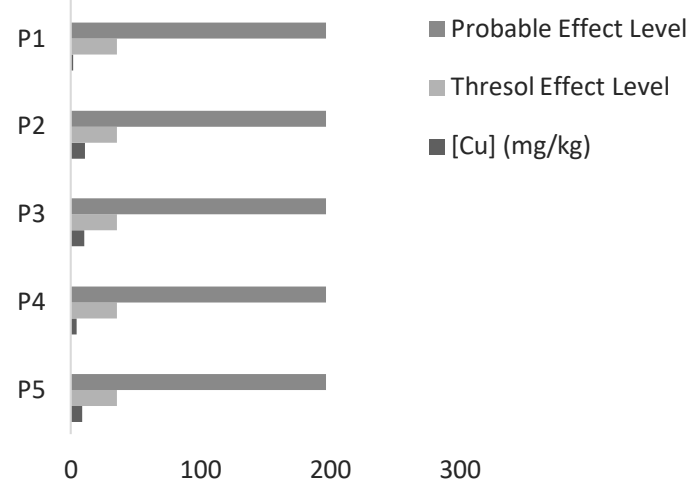

Cobre (Cu) - Sedimento de Planície

b)

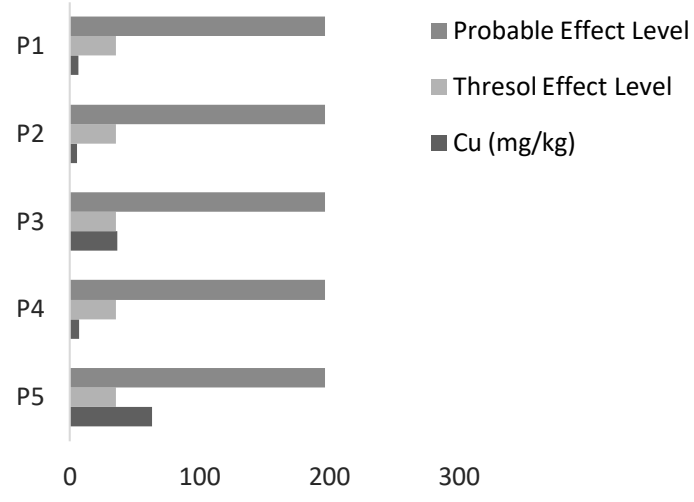

Figura 5: Resultados analíticos do Cobre $(\mathrm{Cu})$, sedimento de leito $(\mathrm{A})$ e sedimento de planície (B) e comparação com parâmetros de referência.

$\mathrm{Na}$ interação físico-química no sedimento de planície, devido o cobre ter maior adsorção com material orgânico, mesmo que a matéria orgânica presente na camada superficial esteja com teor baixo, o cobre ligase aos outros cátions divalentes, em função da complexação com substâncias orgânicas ser diferente de outros metais. Nesse sentido Pedrozo e Lima (2001) afirmam que

quando a quantidade de matéria orgânica é baixa, a concentração de minerais ou de ferro, manganês e óxidos de alumínio tornam-se importantes na adsorção de cobre. Como o cobre liga-se mais fortemente ao solo que outros cátions divalentes, sua distribuição é menos influenciada pelo pH do que outros metais (PEDROZO e LIMA, 2001, p.47).

Já na análise de água, todos os valores estão abaixo do limite de detecção instrumental $(<\mathrm{LD})$. De acordo com Pedrozo e Lima (2001), a disponibilidade é geralmente pequena para as concentrações totais de metais em água. Vários processos (adsorção a óxidos metálicos, argila, material particulado em suspensão, bioacumulação) influenciam a disponibilidade do cobre no sistema aquático. Além disso, no âmbito da saúde, Poleto e Castilhos (2008) frisam que a intoxicação aguda por cobre é rara e os sintomas incluem salivação, náusea, vômito e diarreia.

O Níquel (Ni) teve uma representatividade baixa, abaixo do limite do TEL nos sedimentos de planície e de leito (Figura 6). Referente a esse elemento, há uma baixa frequência de ocorrência de impacto no ambiente, apesar de Poleto e Castilhos (2008) observarem serem de toxicidade média-alta, e derivado de fontes como asfaltenos, queima de combustíveis fósseis, fundição de metais, entre outros, além de ser um metal reconhecido causador de dermatite, envolvendo erupções e eczemas. Nas amostras de água os valores de todos os pontos foram abaixo do limite de detecção instrumental. 
a)

Níquel (Ni) - Sedimento de leito

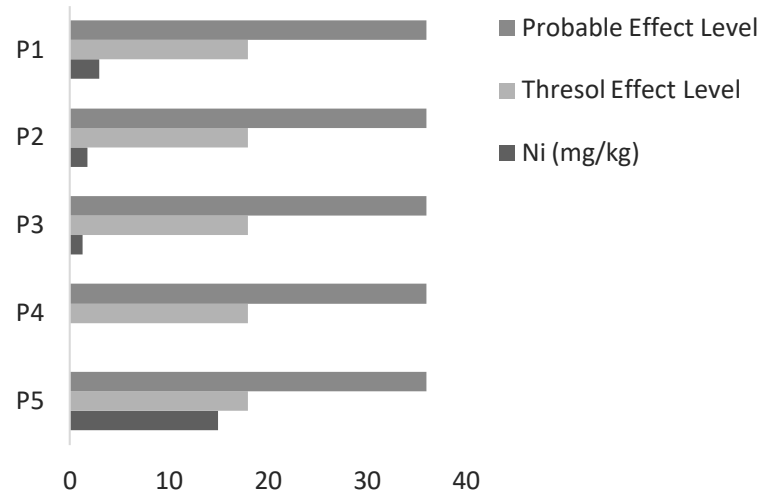

b)

\section{Níquel (Ni) - Sedimento de Planície}

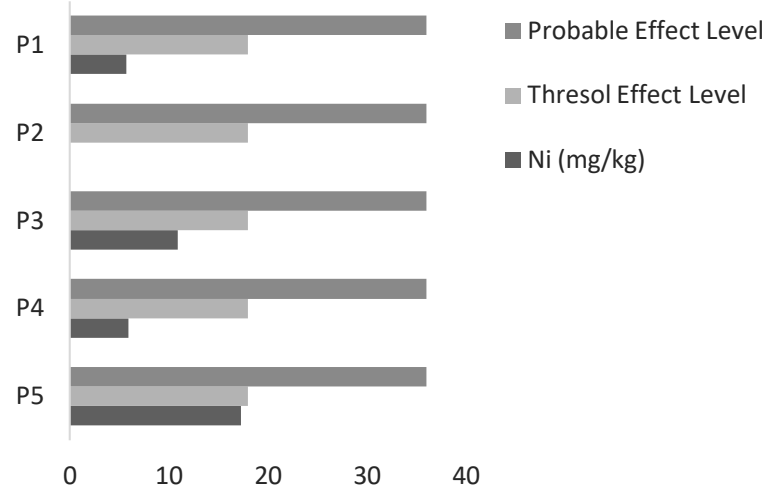

Figura 6: Resultados analíticos do Níquel (Ni), sedimento de leito (A) e planície (B) e comparação com parâmetros de referência.

A concentração do teor de Cádmio $(\mathrm{Cd})$ foi abaixo do limite de detecção instrumental $(<\mathrm{LD})$ em todos os compartimentos analisados (Tabela 1). Cesar et al. (2014) também obtiveram teores de cádmio abaixo do limite de detecção instrumental $(0,2 \mathrm{mg} / \mathrm{kg})$ no município de Belford Roxo (RJ).

Os dados do elemento Chumbo $(\mathrm{Pb})$ podem ser visualizados no conjunto de gráficos (Figura 7). No sedimento de planície do ponto 5 encontrou-se concentração de $36,5 \mathrm{mg} / \mathrm{kg}$, acima dos valores orientados do TEL. Acredita-se que é devida à contribuição de fontes proveniente de lixões, outra fonte comum de contaminação dos sistemas aquáticos superficiais (GUILHERME et al., 2005) como, por exemplo, o "lixão de Babi”, uma área de deposição irregular às margens do rio Botas, no município de Belford Roxo.

a)

Chumbo (Pb)-Sedimento de Planície

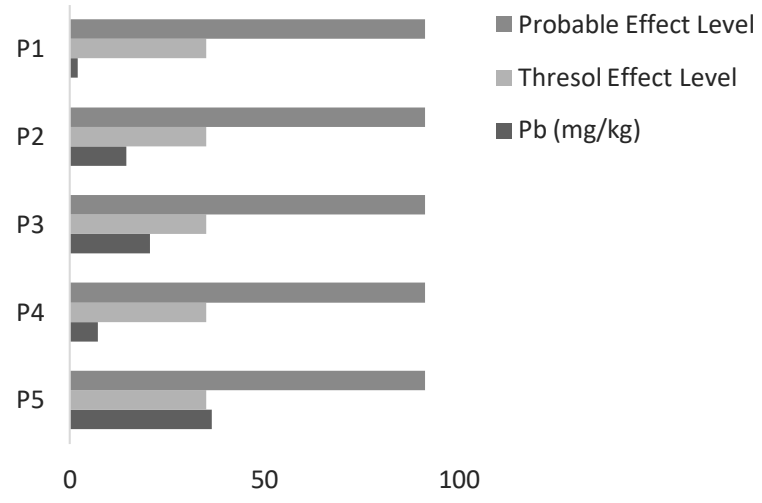




\section{Chumbo (Pb)-Água}

b)

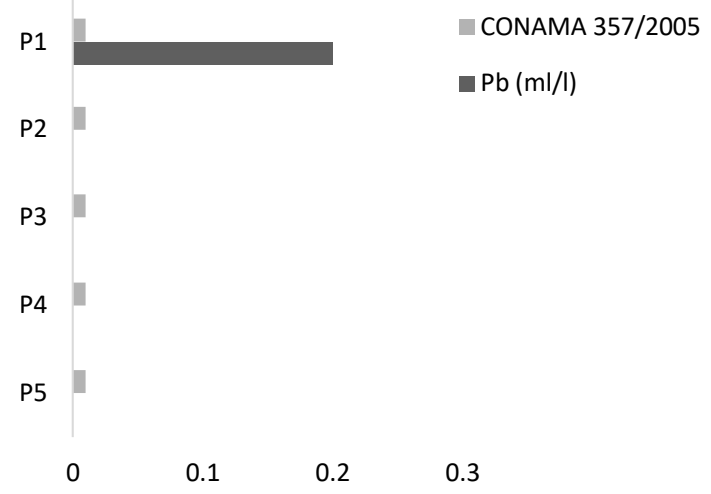

Figura 7: Resultados analíticos do Chumbo $(\mathrm{Pb})$, sedimento de planície $(\mathrm{A})$ e águas superficiais $(\mathrm{B})$ e comparação com parâmetros de referência.

Portanto, pode-se considerar uma fonte antropogênica visto que os lixões contêm diversos tipos de materiais, e esse elemento está presente em diversos objetos. Nesse sentido, Poleto e Castilhos (2008) ressaltam que soldas, baterias, tintas, gasolinas, encanamentos e queima de combustíveis fósseis são derivados de chumbo. Os demais pontos de solo de planície (1,2,3 e 4) e todos os de sedimento de leito apresentaram concentração abaixo do limite do TEL, possuindo uma baixa frequência de impacto no meio por esse elemento.

As análises de chumbo na água mostram somente o ponto 5 com resultado acima do valor orientado $(0,01$ $\mathrm{mg} / \mathrm{l}$ ) pela Resolução CONAMA (2005), com concentração de $0,2 \mathrm{mg} / \mathrm{l}$. Nos demais pontos os valores das análises em água foram abaixo do limite de detecção $(<\mathrm{LD})$.

Considerando o resultado do ponto 5, essa concentração pode estar associada ao material particulado depositado por transporte atmosférico ou pelo transporte pela água. Landrigan et al. (1975) afirmam que a dispersão e deposição dos particulados de chumbo no ambiente dependem amplamente das condições meteorológicas tais como: mudanças de correntes eólicas, temperatura na camada do ar e vento, sendo esse um importante parâmetro meteorológico no processo distribuição da poluição atmosférica por chumbo numa determinada região, podendo transportá-lo a longa distância de seu ponto de emissão. Vale observar que uma pedreira, situada a $2.885 \mathrm{~km}$ do ponto 1 , nas encostas da Serra de Madureira, nome local para esse setor do Maciço Marapicu-Gericinó-Mendanha, está em pleno funcionamento, o que poderia permitir esse tipo de transporte para a área do ponto 1.

Conforme Paoliello (2001), a alta concentração na água pode ser devido aos condicionantes (pH, sais dissolvidos, complexantes orgânicos) que influenciam a sua permanência na fase aquosa ou como precipitado. Também pode estar complexado tanto com compostos orgânicos naturais (ácidos húmicos ou flúvicos) como compostos de origem antropogênica (por exemplo, ácido etileno diamino tetracético) (PAOLIELLO, 2001). Ainda de acordo com Passagli (2011), a exposição crônica ao chumbo pode causar os seguintes sintomas: perda de memória, dor de cabeça, irritabilidade, quando atinge o sistema nervoso. A toxicidade aguda apresenta inflamação gastrointestinal, vômitos e diarreias. Isso enfatiza os riscos à saúde humana nessa área visto que pode ocorrer exposição ao material particulado de chumbo.

O Zinco (Zn) não teve uma representatividade em sedimento de leito. Já na planície houve uma maior concentração nos pontos 3 e 5, ultrapassando o valor do TEL, porém ainda com uma ocorrência de baixa frequência de efeitos adversos. Nos demais também apresentou valores abaixo do TEL (Figura 8). Quando em baixas concentrações, o zinco é considerado um micronutriente essencial para o ser humano. Para Cesar et al. (2014), é um bom indicador antropogênico de contaminação por despejos de efluentes industriais, fator esse que pode esclarecer a concentração de $114 \mathrm{mg} / \mathrm{kg}$ encontrada em sedimentos dragados em sua área de estudo.

A concentração de zinco encontrada no P5, em sedimento de planície próximo a foz do Rio Botas, foi de $242,2 \mathrm{mg} / \mathrm{kg}$, maior do que o quantificado no estudo de Cesar et al. (2004) e acima do limite orientado pelo TEL, justamente por ser uma área de convergência de todas as cargas de efluentes, podendo também considerar a influência lixão de Babi, próximo ao ponto 5. Segundo Guilherme et al. (2005), lixões utilizados por indústrias de "fundo-de-quintal", por exemplo, são uma fonte comum de elemento-traço (as grandes e 
médias indústrias não só dispõem de seus próprios sistemas de descarte, como também são mais facilmente controladas).

a)

Zinco (Zn)- Sedimento de Planície

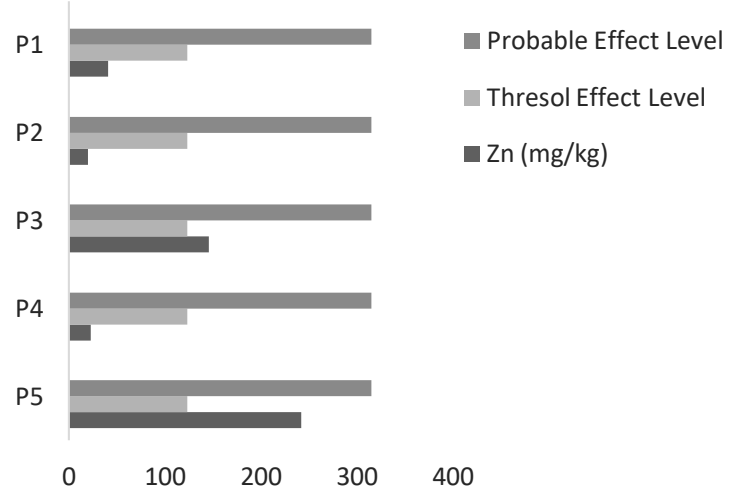

Zinco (Zn)- Água

b)

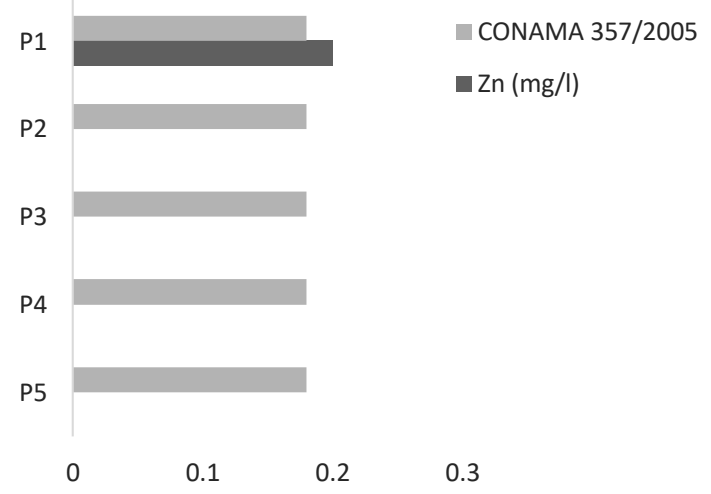

Figura 8: Resultados analíticos do Zn, sedimento de planície (A) e água (B).

À vista disso, os elementos-traço analisados $(\mathrm{Pb}, \mathrm{Cr}, \mathrm{Cu}, \mathrm{Zn})$ apresentaram concentrações elevadas nas seções de médio e baixo curso da bacia hidrográfica do rio Botas, tornando esses pontos poluídos em função da sua correlação com a densa urbanização (Figura 9), com a contribuição das poluições advindas de fontes difusas de esgoto doméstico e despejos industriais in natura (Tabela 1), principalmente nas áreas de proteção permanente do rio, mas não exclusivamente, já que a urbanização é significativa em toda a bacia de drenagem.

Considerando os dados obtidos, as baixas concentrações dos elementos-traço biodisponíveis no compartimento de planície fluvial podem estar relacionadas com a alta carga de matéria orgânica presente no sistema de drenagem, que contribui para a redução da biodisponibilidade e a mobilidade geoquímica dos contaminantes nos solos e sedimentos. Conforme afirma Souza et al. (2015), a presença de matéria orgânica desempenha um papel importante, quer seja em compartimento aquático ou sedimentar, com propriedades singulares como a complexação ou adsorção de íons traço, resultando na imobilização e redução de seus estados de valência com mudanças nas suas propriedades químicas.

Entretanto, os valores de elementos com baixa representatividade nos sedimentos de planícies e leito podem ter correlação tanto com a presença dessa matéria orgânica em sedimentos, como com a presença de argilominerais, que atuam como agentes redutores da ecotoxidade de elemento-traço, por meio da troca catiônica por meio do processo complexo de adsorção que, junto com substâncias orgânicas e inorgânicas são capazes de retomar os íons ou moléculas da solução do solo ou da superfície do solo, ficando retidos nas superfícies dos sólidos, por meio das ligações químicas ou físicas (CESAR et al. 2012). Conforme afirmam Cesar et al. (2012; 2014), a presença de argilomineral expansivo (esmectita), mesmo em baixas proporções, pode atuar no sequestro geoquímico de metais, através da capacidade de troca catiônica, reduzindo a concentração na solução do solo. 


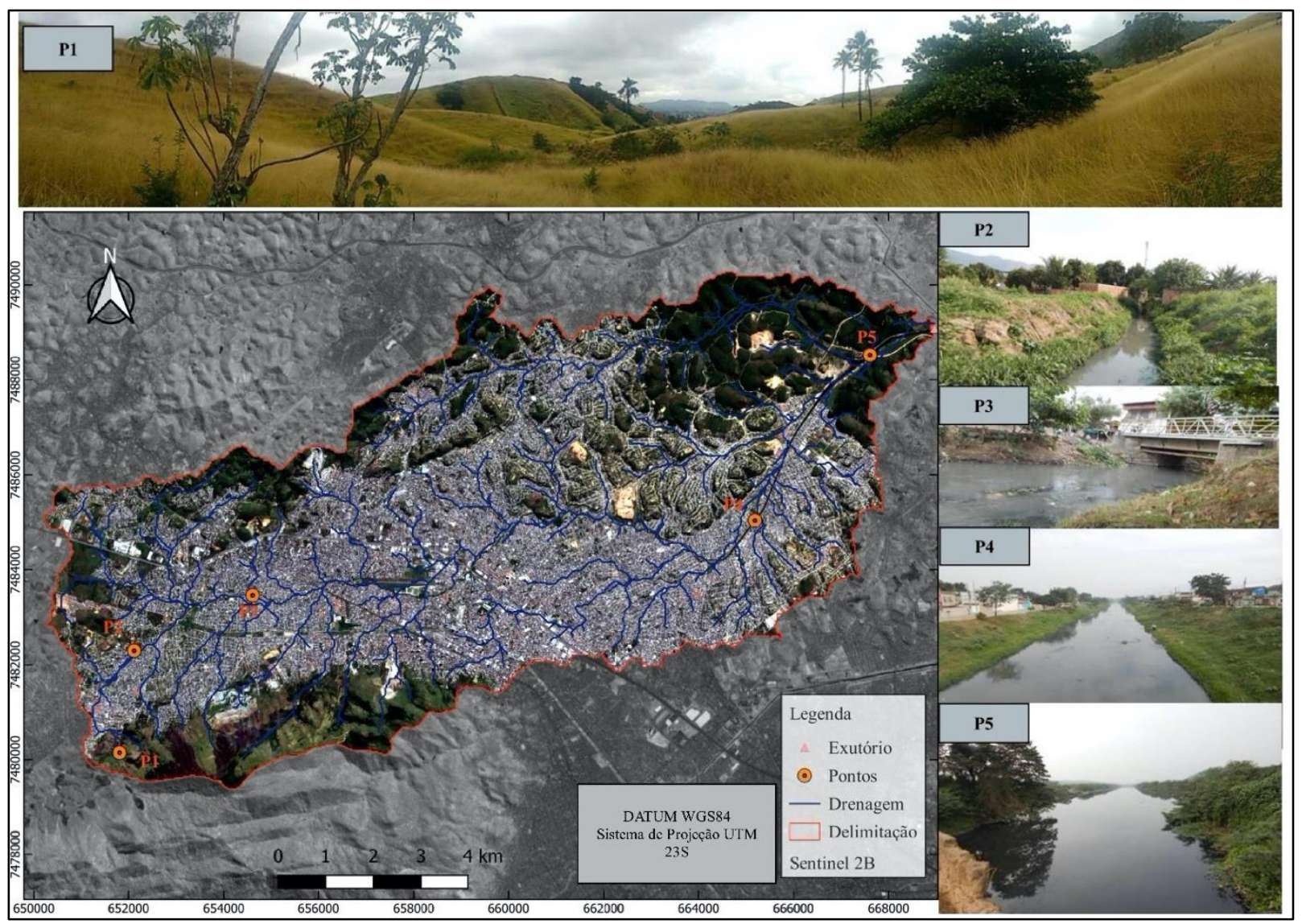

Figura 9: Observação da área e dos pontos amostrais na bacia hidrográfica do rio Botas.

Tabela 1: Síntese dos resultados analíticos.

\begin{tabular}{|c|c|c|c|c|c|c|c|c|c|c|c|c|c|c|c|}
\hline Localiz & \multicolumn{3}{|c|}{$\begin{array}{c}\text { Curso Superior } \\
\text { (Nascente) }\end{array}$} & \multicolumn{3}{|c|}{ Curso Superior } & \multicolumn{3}{|c|}{ Curso Superior } & \multicolumn{3}{|c|}{ Curso Inferior } & \multicolumn{3}{|c|}{$\begin{array}{c}\text { Curso Inferior } \\
\text { (Exutório) }\end{array}$} \\
\hline Ponto & \multicolumn{3}{|c|}{ P1 } & \multicolumn{3}{|c|}{$\mathbf{P 2}$} & \multicolumn{3}{|c|}{$\mathbf{P 3}$} & \multicolumn{3}{|c|}{ P4 } & \multicolumn{3}{|c|}{ P5 } \\
\hline $\begin{array}{l}\text { Comp. } \\
\text { Amb }\end{array}$ & $\mathbf{A}$ & SL & SP & $\mathbf{A}$ & $\mathbf{S P}$ & SL & $\mathbf{A}$ & SL & SP & $\mathbf{A}$ & SL & SP & $\mathbf{A}$ & SL & SP \\
\hline $\mathrm{Cr}$ & 0,8 & 8,1 & 8,3 & 0,1 & 6,4 & 5,2 & - & 5,8 & 12,7 & 1,5 & - & 15,4 & 0,6 & 42,2 & 24,6 \\
\hline DP & 1,3 & \multicolumn{2}{|c|}{2,2} & 1,3 & \multicolumn{2}{|c|}{2,2} & 1,3 & \multicolumn{2}{|c|}{2,2} & 1,3 & \multicolumn{2}{|c|}{2,2} & 1,3 & \multicolumn{2}{|c|}{2,2} \\
\hline $\mathrm{Cu}$ & - & 2,0 & 6,8 & - & 10,8 & 5,4 & - & 10,2 & 36,6 & - & 4,6 & 7,3 & - & 8,6 & 63,4 \\
\hline DP & 0,7 & \multicolumn{2}{|c|}{0,7} & 0,7 & \multicolumn{2}{|c|}{0,7} & 0,7 & \multicolumn{2}{|c|}{0,7} & 0,7 & \multicolumn{2}{|c|}{0,7} & 0,7 & \multicolumn{2}{|c|}{0,7} \\
\hline $\mathbf{N i}$ & - & 3,0 & 5,7 & - & 1,8 & 0 & - & 1,3 & 10,9 & - & 0 & 5,9 & - & 15 & 17,9 \\
\hline DP & 0,7 & \multicolumn{2}{|c|}{1,2} & 0,7 & \multicolumn{2}{|c|}{1,2} & 0,7 & \multicolumn{2}{|c|}{1,2} & 0,7 & \multicolumn{2}{|c|}{1,2} & 0,7 & \multicolumn{2}{|c|}{1,2} \\
\hline Cd & - & - & - & - & - & - & - & - & - & - & - & - & - & - & - \\
\hline DP & 0,2 & \multicolumn{2}{|c|}{0,3} & 0,2 & \multicolumn{2}{|c|}{0,3} & 0,2 & \multicolumn{2}{|c|}{0,3} & 0,2 & \multicolumn{2}{|c|}{0,3} & 0,2 & \multicolumn{2}{|c|}{0,3} \\
\hline $\mathbf{P b}$ & 0,2 & 3,3 & 2,0 & - & 2,7 & 14,6 & - & 7,8 & 20,6 & - & - & 7,2 & - & 2,4 & 36,5 \\
\hline DP & 2,0 & \multicolumn{2}{|c|}{8,4} & 2,0 & \multicolumn{2}{|c|}{8,4} & 2,0 & \multicolumn{2}{|c|}{8,4} & 2,0 & \multicolumn{2}{|c|}{8,4} & 2,0 & & 4 \\
\hline $\mathbf{Z n}$ & 0,2 & 22,9 & 40,9 & - & 46,2 & 20 & - & 40,2 & 145,5 & - & 27,5 & 23 & - & 9,0 & 242,2 \\
\hline DP & 7,5 & & & 7,5 & & & 7,5 & & & 7,5 & 4 & & 7,5 & & 3 \\
\hline
\end{tabular}

Legenda:

Localiz.= Localização; Comp. Amb. = Compartimentação Ambiental

A - Água (mg/l); SL - Sedimento de leito(mg/kg); SF - Sedimento de Planície (mg/kg).

(-) <LD Abaixo do limite de detecção; DP- desvio padrão.

Verde: Concentração abaixo do limite do TEL e do CONAMA 357/2005.

Vermelho: Concentração acima do limite do TEL ou do CONAMA 357/2005. 
A concentração nos compartimentos ambientais encontrados abaixo do limite do TEL, com probabilidade baixa de riscos de contaminação e efeitos adversos no sistema fluvial, atribui-se ao fato de apenas uma fração em fase trocável desse conteúdo estar biodisponível no ambiente. Souza et al. (2015) destacam que pode ocorrer que apenas uma fração do conteúdo metálico total esteja biodisponível, de modo que a toxicidade dos sedimentos varia não em função das concentrações dos metais, mas da forma como eles estão fixados a sedimentos.

As análises nas amostras de água demonstraram uma limitação nesse compartimento ambiental, apresentando valores abaixo dos limites de detecção instrumental. Sobre isso, Guilherme et al. (2005) consideram a água ser um marcador ambiental de quadro momentâneo, tornando-se difícil a deteç̧ão instrumental de elementos-traço, diferente dos solos e sedimentos que são depositados na carga de fundo do rio e guardam um registro histórico ambiental da contaminação de um corpo d'água. Quanto ao desvio padrão das amostras, obteve-se uma variação entre 0,2 a 8,4, indicando heterogeneidade no conjunto de dados.

Ressalta-se que as Áreas de Proteção Permanentes (APP) urbanas da bacia hidrográfica do rio Botas estão em estado de degradação, comprometendo a estrutura superficial da paisagem. São áreas com solo exposto que se alternam com outras que sofreram intervenção via impermeabilização no processo de expansão da cidade, que combinam uma acentuação de processos erosivos que contribuem para a deposição material nas planícies fluviais (e assoreamento dos leitos dos canais) e eventos de inundações e alagamentos, agravados também pelos despejos de resíduos sólidos. Dunne e Leopold (1978), ao discutir a qualidade da água dos rios, ou seja, os atributos físicos, químicos e biológicos que afetam a sua disponibilidade para variados usos, destacam a maior complexidade da química da água dos canais superficiais em comparação com as águas subterrâneas devido a maior variabilidade de fluxos de água que chegam ao canal por várias rotas. Os autores também observam que o escoamento superficial da água da chuva nas áreas urbanas pode carrear alta concentração de rejeitos orgânicos para os canais.

Consequentemente, o solo e as águas superficiais se tornam, portanto, vetores de propagação de poluição para a biota e população em função do uso do solo nesses ambientes. Nesse recorte espacial da área de estudo, como marca do "Tecnógeno" (TER-STEPANIAN, 1988) ou do "Antropoceno" (CRUTZEN e STOERMER, 2000), é comum o registro de ocupações de populações em vulnerabilidade socioeconômica, sob o passivo ambiental de solos águas superficiais contaminados, associado à histórica ineficácia da gestão pública no que tange a gestão territorial e ambiental. Nesse sentido, é importante ressaltar o risco ecológico e social no sistema fluvial com a presença elevada de elementos-traço no meio ambiente, sob o processo de bioacumulação ou biomagnificação, e a sua conexão com a saúde humana visto que não são biodegradáveis e podem ser bioacumulativos no ambiente e em organismos, como ressaltam Poleto e Castilhos (2008). Diante da identificação de geoindicadores com elevado potencial tóxico nos compartimentos ambientais, levanta-se a hipótese desses cursos fluviais degradados serem vias facilitadoras de agentes patogênicos, em função da dinâmica do transporte fluvial de poluentes nessa bacia de drenagem urbanizada.

\section{Conclusões}

As análises dos geoindicadores químicos indicam a poluição de água e sedimentos pelos metais, $\mathrm{Cr}, \mathrm{Cu}$, $\mathrm{Pb}$ e $\mathrm{Zn}$, com base nos valores de referência da NOAA (BUCHMAN, 2008) e CONAMA (2005), na bacia hidrográfica do rio Botas. As concentrações pseudo-total observadas, que ultrapassam os limites de referência considerados, foram as seguintes: para o analito do cromo os resultados para o sedimento de leito foram 42,2 (mg/kg) no ponto 5 e para água obteve-se $0,8(\mathrm{mg} / \mathrm{l})$ no ponto1, 1,5 $(\mathrm{mg} / \mathrm{l})$ ponto $4 \mathrm{e}, 0,6(\mathrm{mg} / \mathrm{l})$ no ponto 5. No cobre foram registrados nos pontos 3 e 5 do sedimento de planície os respectivos valores de $36,6(\mathrm{mg} / \mathrm{kg})$ e $63,4(\mathrm{mg} / \mathrm{kg})$. O chumbo resultou em $36,5(\mathrm{mg} / \mathrm{kg})$ no sedimento de planície do ponto 5 e, na água $0,2(\mathrm{mg} / \mathrm{l})$ no ponto 1 . O zinco apresentou $0,2(\mathrm{mg} / \mathrm{l})$ na água do ponto 1 , e no sedimento de planície um aumento do ponto 3 ao 5 , com valores $145,5(\mathrm{mg} / \mathrm{kg})$ e $242,2(\mathrm{mg} / \mathrm{kg})$, respectivamente. Portanto, esses pontos e compartimentos ambientais são considerados poluídos, podendo apresentar efeitos adversos no sistema ambiental.

Nessa área, que apresenta um longo histórico de degradação, verificou-se que os resultados dos pontos poluídos por elementos-traço têm, além das fontes de metais geogênicas, a adição da ação antropogênica local com a presença de fontes pontuais (indústrias) e fontes difusas (esgoto doméstico in natura) que corroboram com o aumento de metais-traço em bacias urbanas. Devido às diferentes condições da cobertura e uso da terra, que influenciam na qualidade da água superficial e sedimentos, os resultados apresentaram um aumento gradativo em direção à jusante do rio. 
A deficiência no gerenciamento dos serviços de saneamento básico nos municípios do entorno da Baía de Guanabara traz consigo diversos problemas sanitários e de saúde pública. Portanto, nos alerta para a relevância de uma melhor gestão dos recursos hídricos, vetores de patógenos, ressaltando a necessidade de medidas emergenciais em curto, médio e longo prazo, nessa bacia hidrográfica e nas áreas adjacentes.

\section{Agradecimentos}

Ao apoio institucional e coletivo que permitiu a realização da pesquisa do Laboratório de Meio Ambiente do Instituto Federal de Educação, Ciência e Tecnologia do Rio de Janeiro (IFRJ), ao Laboratório Química e Poluição de Solo do Departamento de Solos do Departamento de Solos da Universidade Federal Rural do Rio de Janeiro (UFRRJ) pelo auxílio na etapa de absorção atômica, em especial aos agrônomos $\operatorname{Dr}^{\mathbf{a}}$ Adriana França e $\operatorname{Dr}^{\circ}$ Jair Guedes pelo apoio direto e ensinamentos, e Laboratório de Geociências e Estudos Ambientais do Departamento de Geografia do Instituto Multidisciplinar da UFRRJ. Aos pareceristas da Revista do Departamento de Geografia da USP pelas importantes correções e sugestões no processo de revisão do artigo.

\section{Referências}

AMARAL, R. D.; GUTJAHR, M. R. Desastres naturais (Série Cadernos de Educação Ambiental, 8). São Paulo: IG/SMA, 2011.

BRASIL. Lei $\mathrm{n}^{\mathrm{o}}$ 12.651, de 12 de maio de 2012. Institui o novo código florestal. Diário Oficial da União, Brasília, DF, 28 de maio de 2012. Disponível em: <http://www.planalto.gov.br/ccivil_03/_Ato2011014/2012/Lei/L12651.htm\#art83>. Acesso: 24 set. 2019.

BRASIL. Ministério de Saúde. Doenças infecciosas e parasitárias: guia de bolso. 8 ed. Brasília: Ministério da Saúde, 2010.2 Disponível em: http://bvsms.saude.gov.br/bvs/publicacoes/doencas_infecciosas_parasitaria_guia_bolso.pdf>. Acesso: 18 mai. 2020.

BUCHMAN, M. F. NOAA Screening Quick Reference Tables, NOAA OR\&R Report 08-1, Seattle WA, Office of Response and Restoration Division, National Oceanic and Atmospheric Administration, 2008. 34 p.

CESAR, R.; COLONESE, J.; SILVA, M.; EGLER, S.; BIDONE, E., CASTILHOS, Z.; POLIVANOV, H. Distribuição de mercúrio, cobre, chumbo, zinco e níquel em sedimentos de corrente da bacia do Rio Piabanha, Estado do Rio de Janeiro. Geochimica Brasiliensis, v. 25, n. 1, p. 35-45, 2012. http://dx.doi.org/10.21715/gb.v25i1.330

CESAR, R.; SOUSA, M. A.; POLIVANOV, H.; BARROSO, E.; AlVARO, T.; COLONESE, J.; CASTILHOS, Z. Disposição terrestre de sedimentos de dragagem: ecotoxicidade, biodisponibilidade de metais e estudo de caso em Belford Roxo (RJ). Geociências (São Paulo), v. 33, n. 3, p. 416-428, 2014.

CONAMA. Conselho Nacional do Meio Ambiente. Resolução 557 de 17 de março de 2005, publicado no DOU $n^{\circ}$ 053, de 18/08/2005: Dispõe sobre a classificação dos corpos de água e diretrizes ambientais para o seu enquadramento, bem como estabelece as condições e padrões de lançamento de efluentes, e dá outras providências. Disponível em: <http://www2.mma.gov.br/port/conama/legiabre.cfm?codlegi=459>. Acesso: 12 fev. 2019.

COLTRINARI, L; MCCALL, J. H. Geoindicadores: Ciência da Terra e Mudanças Ambientais.Revista do Departamento de Geografia (Universidade Estadual de São Paulo), vol. 09, 1995.

CRAUL, P. J. A description of urban soils and their desired characteristics. Journal of Arboriculture, v. 11, n. 11, p. 330-339, 1985.

CRUTZEN, P. J.; STOERMER, E. F. The Anthropocene: Global Change Newsletter. The Royal Swedish Academy of Sciences Stockholm, Sweden, v. 41, p. 14-17, 2000. 
DA SILVA, C. P; DA SILVEIRA, E. L; DE CAMPOS, S. X. Environmental pollution by heavy metals in the Sao Joao River basin, southern Brazil. Environmental Earth Sciences, v. 76, n. 16, p. 554, 2017.

DOS REIS, D. A.; NASCIMENTO, L. P.; DE ABREU, A. T.; JÚNIOR, H. A. N.; ROESER, H. M. P.; DA FONSECA SANTIAGO, A. Geochemical evaluation of bottom sediments affected by historic mining and the rupture of the Fundão dam, Brazil. Environmental Science and Pollution Research, v. 27, n. 4, p. 43654375, 2020.

DUNNE, T.; LEOPOLD, L. B. Water in environmental planning. São Francisco: W.H. Freeman, 1978. 818 p.

FIOCRUZ. Água Brasil: Sistema de avaliação da qualidade da água e saneamento. Glossário de doenças relacionadas à água. Disponível em: 〈https://www.aguabrasil.icict.fiocruz.br/index.php?pag=doe> Acesso: 18 mai. 2020.

FNEM - Fórum Nacional de Entidades Metropolitanas. Institucional. Disponível em <http://fnembrasil.org > Acesso: 30 out. 2020.

GUILHERME, L. R. G., MARQUES, J. J., PIERANGELI, M. A. P., ZULIANI, D. Q., CAMPOS, M. L.; MARCHI, G. Elementos-traço em solos e sistemas aquáticos. Tópicos em ciências do solo, 4, 345-390, 2005. INEA. Resolução CERHI-RJ $n^{\circ} 107$ de 22 de maio de 2013. Nova definição das regiões hidrográficas do estado do rio de Janeiro. <http://www.inea.rj.gov.br/cs/groups/public/documents/document/zwff/mda5/ edisp/inea_009662.pdf>.

Acesso: 14 nov. 2019.

IUSS WORKING GROUP WRB. International soil classification system for naming soils and creating legends for soil maps. World reference base for soil resources 2014, update 2015, v. 106, 2015.

LADEIRA, F. S. B. Solos em Áreas Urbanas: Reflexões e Possibilidades de análise. In: SILVA, C. A. (Org) Geografia e Natureza: experiências e abordagens de pesquisas. Dourados: UFGD, 2012. p. 201-226.

LANDRIGAN, P. J.; GEHLBACH, S. H.; ROSENBLUM, B. F.; SHOULTS, J. M.; ROBERT, P. E.; CANDELARIA, M.; SANDERS, J. F. Epidemic lead absorption near an ore smelter: the role of particulate lead. New England Journal of Medicine, v. 292, n. 3, p. 123-129, 1975.

NASCIMENTO, L. P. D.; REIS, D. A.; ROESER, H. M. P.; SANTIAGO, A. D. F. Avaliação geoquímica de metais em sistemas fluviais afetados por atividades antrópicas no Quadrilátero Ferrífero. Engenharia Sanitaria e Ambiental, v. 23, n. 4, p. 767-778, 2018. https://doi.org/10.1590/s1413-41522018165852

PAOLIELLO, M. Ecotoxicologia do chumbo e seus compostos. Cadernos de Referencia Ambiental, 003. CRA, p. 1-141, 2001.

PASSAGLI, M. Toxicologia Forense. 3. Ed. São Paulo: Millennium, 2011. 318 p.

PEDRON, F., MENEZES, F., BOTELHO, M., AZEVEDO, A., \& DALMOLIN, R. Urban soils. Ciência Rural, v. 34, n. 5, p. 1647-1653, 2004.

PEDROZO, M. D. F. M.; LIMA, I. V. D. Ecotoxicologia do cobre e seus compostos. In: Cadernos de Referencia Ambiental, 002. CRA, p.128, v.2, 2001.

PELOGGIA A.U.G. O problema estratigráfico dos depósitos tecnogênicos. In: CONGRESSO DA ASSOCIAÇÃO BRASILEIRA DE ESTUDOS DO QUATERNÁRIO, 9., Recife, Anais Eletrônicos, 2003.

POLETO, C; CASTILHOS, Z. C. Impacto por poluição difusa de sedimentos em bacias urbanas. Ambiente e Sedimentos. Porto Alegre: Associação Brasileira de Recursos Hídricos-ABRH, p. 193-227, 2008.

POLETO, C. Bacias hidrográficas urbanas. In: POLETO, C. Bacias hidrográficas e recursos hídricos. Rio de Janeiro: Interciência, 2014. 272 p. (p. 29-47). 
RIO DE JANEIRO. Lei Complementar $n^{\circ}$ 158, de 26 de dezembro de 2013, que dispõe sobre a Região Metropolitana do Rio de Janeiro. Disponível em <https://govrj.jusbrasil.com.br/legislacao/112299831/lei-complementar-158-13-rio-de-janeiro-rj> Acesso: 30 out. 2020.

REBELlO, A. de L.; PONCIANO, C. R.; MELGES, L. H. Avaliação da produtividade primária e da disponibilidade de nutrientes na Baía de Guanabara. Anais da Academia Brasileira de Ciências, v. 60, n. 4, p. $419-430,1988$.

SILVA, C. S. D; PEDROZO, M. D. F. M. Ecotoxicologia do cromo e seus compostos. In: Cadernos de Referencia Ambiental, 005. CRA, v.5, 2001.

SOUZA, V. L.; LIMA, V. L.; HAZIN, C. A.; FONSECA, C. K.; SANTOS, S. O. Biodisponibilidade de metais-traço em sedimentos: uma revisão. Brazilian Journal of Radiation Sciences, v. 3, n. 1A, p.01-13. 2015. https://doi.org/10.15392/bjrs.v3i1A.135

TER-STEPANIAN, G. Beginning of the Tecnogene. Bulletin I. A. E. G., v. 38, p. 133-142. 1988.

TRATA BRASIL. Conheça as principais doenças que o saneamento previne. 2018. Instituto Trata Brasil. Disponível em: <http://www.tratabrasil.org.br/blog/2018/08/07/doencas-saneamento-basico-previne/>. Acesso: 18 mai. 2020.

TRATA BRASIL. Internações por doenças de veiculação hídrica no Brasil. 2019 (a). Instituto Trata Brasil. Disponível em: < http://www.tratabrasil.org.br/blog/2019/05/21/internacoes-de-doencas-por-veiculacaohidrica-no-brasil/>. Acesso: 18 mai. 2020.

TRATA BRASIL. Ranking do saneamento básico. 2019 (b). Instituto Trata Brasil. Disponível em: <http://www.tratabrasil.org.br/estudos/estudos-itb/itb/ranking-do-saneamento-2019) >. Acesso: 23 abr. 2020.

TRATA BRASIL. Ranking do saneamento básico. 2020. Instituto Trata Brasil. Disponível em: <http://www.tratabrasil.org.br/estudos/estudos-itb/itb/ranking-do-saneamento-2020>. Acesso: 23 jan. 2021.

TUCCI, C. E. M. Gestão de águas pluviais urbanas. Programa de Modernização do Setor Saneamento, Secretaria Nacional de Saneamento Ambiental, Ministério das Cidades, 2005.

TUCCI, C. E. M. Urban Waters. Revista Estudos Avançados, vol. 22, n. 63, p. 97-112. 2008. USEPA, EPA. Method 3051A: Microwave assisted acid digestion of sediments, sludges, soils, and oils. 2007.

(1) (9) (2) 